\title{
Characterization of a $\mathrm{Si}-\mathrm{SiO}_{2}$ Mixture Generated from $\mathrm{SiO}(\mathrm{g})$ and $\mathrm{CO}(\mathrm{g})$
}

\begin{abstract}
ANDREA BROGGI, MERETE TANGSTAD, and ELI RINGDALEN
The reaction between $\mathrm{SiO}(\mathrm{g})$ and $\mathrm{CO}(\mathrm{g})$ is a relevant intermediate reaction in the silicon production process. One of the products generated from this gas mixture is called by its color, brown condensate. In this paper, $\mathrm{SiO}(\mathrm{g})$ and $\mathrm{CO}(\mathrm{g})$ are produced from $\mathrm{SiO}_{2}-\mathrm{SiC}$ pellets. The reaction between the two gases occurred on $\mathrm{SiC}$ particles. Inert gas was injected at different flows. The SiC particles were collected, and the brown condensate deposited on them was characterized by electron probe microanalysis, X-ray photoelectron spectroscopy, and focused ion beam preparation samples for transmission electron microscope analysis. The brown condensate consists of a mixture of $\mathrm{Si}$ spheres embedded in a $\mathrm{SiO}_{2}$ matrix. The compound generates in the temperature range from $1400{ }^{\circ} \mathrm{C}$ to $1780{ }^{\circ} \mathrm{C}(1673 \mathrm{~K}$ to $2053 \mathrm{~K})$, and in the $\mathrm{SiO}(\mathrm{g})$ partial pressure range between 0.534 and 0.742 , depending on the inert gas flow. $\mathrm{SiC}$ crystallites are located at the $\mathrm{Si}_{-} \mathrm{SiO}_{2}$ interface. Carbides are believed to generate from the reaction between liquid silicon and $\mathrm{CO}(\mathrm{g})$. Carbides may also precipitate from reaction between dissolved carbon and liquid silicon, but to a minor extent. Both mechanisms are believed to happen above the melting point of silicon and in the softening range of silica.
\end{abstract}

https://doi.org/10.1007/s11663-019-01678-x

(C) The Author(s) 2019

\section{INTRODUCTION}

Metallurgical silicon is produced by the reduction of silica by carbonaceous materials in electric arc furnaces. The thermodynamics of silicon production are well known. The kinetics, which are slow and difficult to predict, have, however, not been studied to the same extent. Process understanding is limited by the large number of reactions happening simultaneously in the silicon production process. Most of them involve intermediate products, such as $\mathrm{SiO}(\mathrm{g})$ and $\mathrm{SiC}$. These two compounds are the main intermediate species in silicon production. As this gas mixture is entering the low-temperature area in the furnace $(1300 \mathrm{~K}$ to $2000 \mathrm{~K}$ ), it will generate condensates and $\mathrm{SiC}$ according to Reactions [1 through 3$]^{[1-4]}$ :

$$
\begin{gathered}
2 \mathrm{SiO}(\mathrm{g}) \rightarrow \mathrm{Si}(\mathrm{s}, \mathrm{l})+\mathrm{SiO}_{2}(\mathrm{~s}, \mathrm{l}) \\
3 \mathrm{SiO}(\mathrm{g})+\mathrm{CO}(\mathrm{g}) \rightarrow 2 \mathrm{SiO}_{2}(\mathrm{~s}, \mathrm{l})+\mathrm{SiC}(\mathrm{s})
\end{gathered}
$$

ANDREA BROGGI and MERETE TANGSTAD are with the Department of Materials Science and Engineering, University of Science and Technology (NTNU), Alfred Getz vei 2b, 7034 Trondheim, Norway. Contact e-mail: andrbrog@ntnu.no ELI RINGDALEN is with the SINTEF, Materials and Chemistry, Alfred Getz vei 2b, 7034 Trondheim, Norway.

Manuscript submitted December 5, 2018.

Article published online September 11, 2019.

$$
\mathrm{SiO}(\mathrm{g})+2 \mathrm{C}(\mathrm{s}) \rightarrow \mathrm{SiC}(\mathrm{s})+\mathrm{CO}(\mathrm{g})
$$

$\mathrm{SiO}(\mathrm{g})$ and $\mathrm{SiC}$ contribute to the formation of silicon in the inner high-temperature zone $(2100 \mathrm{~K}$ to $2400 \mathrm{~K}),{ }^{[5]}$ by Reaction [4].

$$
\mathrm{SiO}(\mathrm{g})+\mathrm{SiC}(\mathrm{s}) \rightarrow 2 \mathrm{Si}(\mathrm{l})+\mathrm{CO}(\mathrm{g})
$$

The mass of condensates in an industrial system can be estimated with the help of thermodynamics and mass balance calculations. Quantitating the mass of condensation products is unfeasible in an industrial oven. Condensates will stick firmly to any surface, and mechanical removal is challenging at high temperatures. The condensate crust is located either at the stoking area, below the electrode or in the central area of the oven. ${ }^{[6-9]}$ In other words, it is very difficult to foresee where condensation would occur, or to confine it in a defined temperature zone.

In industrial- and pilot-scale excavations of silicon and ferrosilicon furnaces, ${ }^{[6-16]}$ the condensate crusts found are of two types. The mixture generated from Reaction [2] is referred to as white condensate. This compound will not be the main focus of this paper. The compound generated through Reaction [1] is called brown condensate. This crust is often found in industrial excavations, but it has never been characterized thoroughly. The only compositional analysis found in literature for industrial samples of brown condensate comes from an industrial excavation performed at Elkem Thamshavn, Norway ${ }^{[6]}$ in 2014. Results show 
that the compound contains porous $\mathrm{SiO}_{2}$ and $\mathrm{SiC}$. No quantitative chemical analysis was performed. Si was expected, as a product of Reaction [1]. Vangskåsen ${ }^{[2]}$ hypothesized that the pores in the condensate are generated by liquid silicon "bleeding" from the silica matrix.

Laboratory-scale experiments reproducing the reaction between $\mathrm{SiO}(\mathrm{g})$ and $\mathrm{CO}(\mathrm{g})^{[2,3,17-20]}$ revealed also the presence of a solid brown deposit. Its microstructure consists of micrometric-sized $\mathrm{Si}$ spheres embedded in a $\mathrm{SiO}_{2}$ matrix, according to backscattered electron scanning electron microscope (BSE-SEM) analysis. Electron probe microscope analysis (EPMA) revealed similar atomic percentages of $\mathrm{Si}$ and $\mathrm{O}$, but a carbon signal up to 10 pct. The compositional analyses of two of these studies ${ }^{[2,18]}$ are gathered in Table I. The results are given with double standard deviation. The values are originating from signals collected over a defocused area of $10 \mu \mathrm{m}$ diameter size. It was not possible to distinguish clearly a carbon-containing phase in the samples, while carrying out local compositional analysis with resolution down to the micrometric level.

In this paper, the product of Reaction [1] will be characterized. New characterization methods will be used with respect to previous studies, such as X-ray photoelectron spectroscopy (XPS), transmission electron microscopy (TEM), and focused ion beam (FIB) sample preparation. The temperature and pressure of the system will be compared with equilibrium calculations. Finally, a mechanism of formation is proposed.

\section{EXPERIMENTAL}

The experimental procedure is reported in this section, based on the study by Broggi and Tangstad. ${ }^{[18]}$ Pellets were made of $\mathrm{SiO}_{2}$ and $\mathrm{SiC}$ powders in the ratio of 2:1 molar. Table II shows the size distribution parameters $\mathrm{d}_{10}, \mathrm{~d}_{50}$, and $\mathrm{d}_{90}$ of the two powders. The pellets were used to produce the gas mixture with a controlled composition. $\mathrm{SiO}_{2}$ is a commercial quartz named Quartz20, whereas $\mathrm{SiC}$ was provided by Washington Mills. The powders were mixed for two hours, and then pelletized at room temperature with water as binder. The pellets' final average diameter ranged between 1 and $2 \mathrm{~mm}$.

The pellets were dried for 6 hours at $110{ }^{\circ} \mathrm{C}(383 \mathrm{~K})$ and calcined for 30 minutes at $1200{ }^{\circ} \mathrm{C}(1473 \mathrm{~K})$. A $600-\mu \mathrm{m}$-size sieve separated the fines after calcination. The pellets were fed into a graphite tube furnace. Twenty grams of pellets were used for each experiment. The $\mathrm{SiO}_{2}$ and $\mathrm{SiC}$ pellets produced $\mathrm{SiO}(\mathrm{g})$ and $\mathrm{CO}(\mathrm{g})$, according to the reaction as given below:

$$
2 \mathrm{SiO}_{2}(\mathrm{~s}, 1)+\mathrm{SiC}(\mathrm{s}) \rightarrow 3 \mathrm{SiO}(\mathrm{g})+\mathrm{CO}(\mathrm{g})
$$

The graphite tube furnace is shown in Figure 1. The tube dimensions are $265 \mathrm{~mm}$ height and $150 \mathrm{~mm}$ diameter. The tube is divided into two parts: a gas production chamber at the bottom, and a reaction chamber mounted above. The $\mathrm{SiO}_{2}-\mathrm{SiC}$ pellets are placed in the crucible in the gas production chamber.
The reaction chamber has an inner diameter of $25 \mathrm{~mm}$ and a height of $150 \mathrm{~mm}$. SiC particles with diameter ranging between 3 and $6 \mathrm{~mm}$ fill the chamber up to 130 $\mathrm{mm}$ from the bottom, as shown in Figure 1. Their purpose is to act as reaction substrate (Figure 2). Before heating the pellets, $\operatorname{Ar}(\mathrm{g})$ or $\mathrm{He}(\mathrm{g})$ were injected as inert gases to purge the oxidizing elements contained in air. The inert gas was flushed during the whole experiment. An alumina tube is used to channel the inert gas to the bottom of the crucible. Both the alumina tube and $\mathrm{SiC}$ substrates are assumed inert to $\mathrm{SiO}(\mathrm{g})$ and $\mathrm{CO}(\mathrm{g})$ reaction at the temperature ranges present in the reaction chamber. The thermal history of the experiment is recorded by C-type thermocouples at different positions in the reaction chamber. The thermocouple is not moved during the experiment. One C-type thermocouple was inserted for each experiment in series 1 and 4 at fixed positions. The thermocouple is shielded by the alumina tube.

A pyrometer is located outside of the gas production chamber. The temperature at the pyrometer was held at $2000{ }^{\circ} \mathrm{C}(2273 \mathrm{~K})$ for all the experiments. Heating and cooling rates were fixed at $50^{\circ} \mathrm{C} / \mathrm{min}$ and $35^{\circ} \mathrm{C} / \mathrm{min}$ with respect to the pyrometer temperature. The inert gas flow and holding time were varied between each series. The inert gas flow rate tunes the partial pressure of $\mathrm{SiO}(\mathrm{g})$, while keeping the $\mathrm{SiO} / \mathrm{CO}$ molar ratio constant. Each series is marked with a number from 1 to 5 , corresponding to the conditions in Table III, and by a letter from $a$ to $e$, defining each experiment repetition.

Backscattered (BSE) and secondary-electron (SE) images were taken using a Hitachi SU-6000 FE-SEM. The working distance was set at $15 \mathrm{~mm}$, and the voltage range between 5 and $20 \mathrm{kV}$. SiC particles were analyzed in situ. Other particles were mounted in traditional epoxy, to focus on morphology and composition. The application of a $20-\mathrm{nm}$-thick carbon coating grants the conductivity of the epoxy, which is necessary for SEM analysis.

The epoxy cast samples were also used for electron probe microanalysis (EPMA). The metallographic analysis was carried out by means of JEOL JXA-8500F. Points showing different contrasts were selected to detect the relative mass percentages of $\mathrm{Si}, \mathrm{O}$, and $\mathrm{C}$.

XPS chemical analysis was performed at the Department of Materials Physics at SINTEF (Trondheim, Norway), on a Kratos Axis Ultra analyzer. The source used was an aluminum monochromatic source $\mathrm{K}_{\alpha}$ at 417 $\mathrm{nm}$ wavelength. The analysis covered an area of $500 \times 700 \mu \mathrm{m}$, whereas the penetration depth reached around $10 \mathrm{~nm}$. The chemical shift of the obtained signals was calibrated by taking the $\mathrm{C}-\mathrm{C}$ bond energy as reference at $285 \mathrm{eV}$. The spectra obtained were analyzed using the software Casa XPS $®$.

FIB preparation was used as a sample preparation technique for TEM analysis. A brown condensate sample was collected from Experiment 1a. A slice of desired extension was collected from the sample surface. The final slice dimension was approximately $30 \mu \mathrm{m} \times$ $30 \mu \mathrm{m} \times 100 \mathrm{~nm}$. A SEM unit is installed in the FIB apparatus, to monitor the procedure. Once extracted, the sample was welded to a dedicated TEM grid. 
Table I. Composition of Brown $\mathrm{Si}_{-} \mathrm{SiO}_{2}$ Condensates Produced at Laboratory Scale

\begin{tabular}{lllll}
\hline Author & Technique Used & Pct Si (at.) & Pct O (at.) & Pct C (at.) \\
\hline Vangskåsen $^{[2]}$ & EPMA, 5 areas & 36.6 & 56.3 & 7.1 \\
Broggi and Tangstad $^{[18]}$ & EPMA, 14 areas & $43.1 \pm 5.2$ & $49.4 \pm 0.8$ & $7.5 \pm 5.2$ \\
\hline
\end{tabular}

Table II. Relevant Size Parameters for Powders Used in Gas-Producing Pellets

\begin{tabular}{lccc}
\hline Powder & $d_{10}(\mu \mathrm{m})$ & $d_{50}(\mu \mathrm{m})$ & $d_{90}(\mu \mathrm{m})$ \\
\hline Quartz20 & 1.700 & 10.73 & 58.38 \\
SiC & 0.179 & 0.955 & 1.876 \\
\hline
\end{tabular}

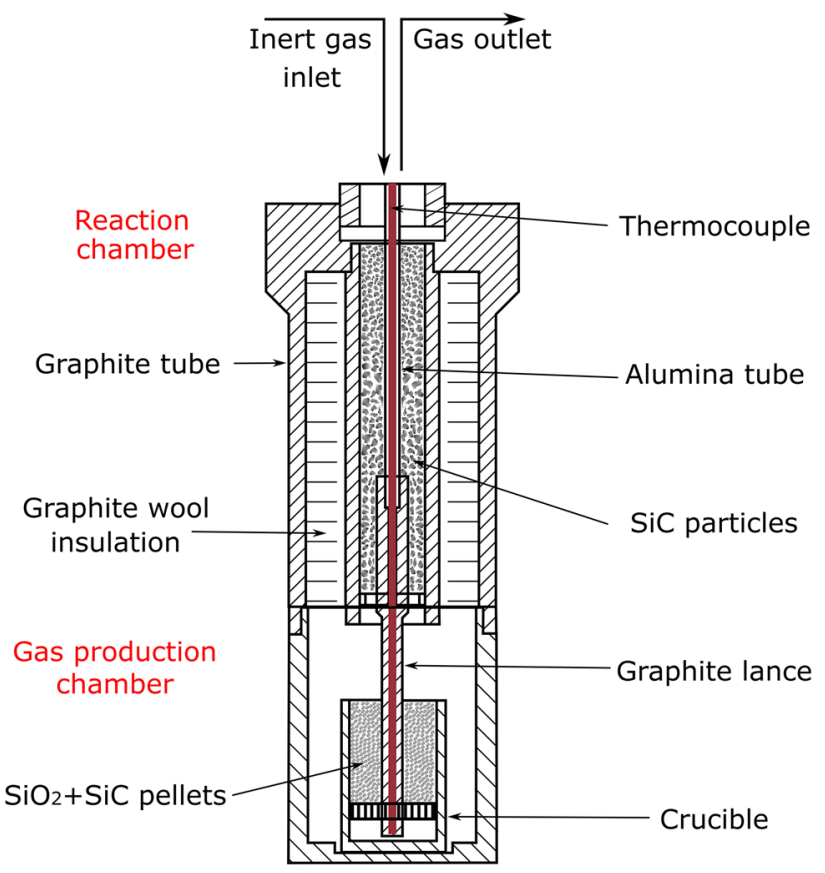

Fig. 1-Schematic overview of the graphite tube furnace setup.

TEM was performed with a double Cs-corrected coldFEG JEOL ARM 200F, operated at $200 \mathrm{kV}$ and equipped with a large solid angle (0.98 sr) Centurio SDD detector for X-ray energy dispersive spectroscopy (EDS) and a Quantum ER GIF for electron energy loss spectroscopy (EELS).

\section{RESULTS}

\section{A. SEM Analysis}

TEM and XPS analyses are the novelty of the current work. The SEM characterization of the same material is reported from Broggi and Tangstad, ${ }^{[18]}$ and will serve as an introduction. New findings are also reported as an extension to the previous work.

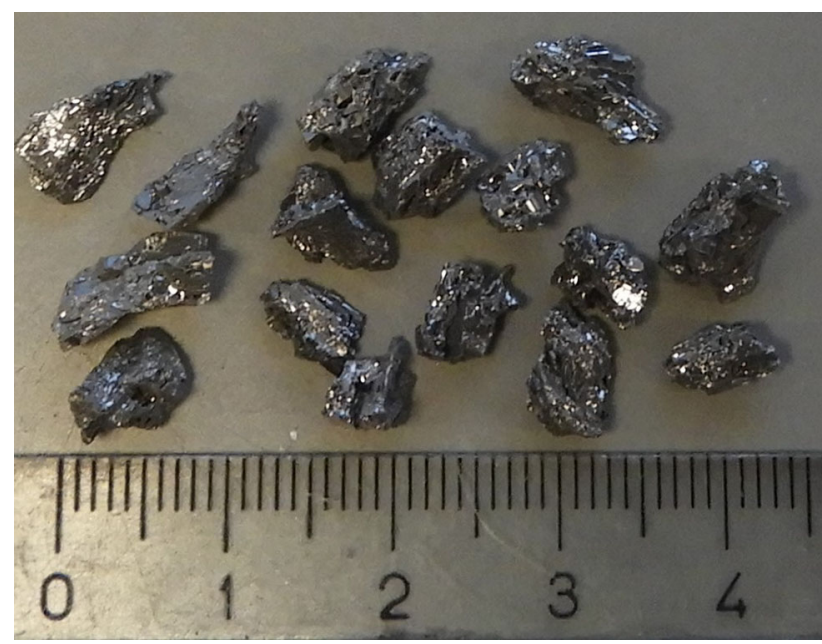

Fig. 2-SiC particles, reaction substrates.

Table III. Holding Times at $2000{ }^{\circ} \mathrm{C}(2273 \mathrm{~K})$ and Gas Flows

\begin{tabular}{lcc}
\hline Series & Time (h) & Gas Flow (1/min) \\
\hline 1 (a-e) & 1 & 0.40 \\
& & $\mathrm{a}=\mathrm{Ar}$ \\
& & $\mathrm{b}-\mathrm{e}=\mathrm{He}$ \\
2 (a) & 1 & $0.10, \mathrm{He}$ \\
3 (a) & 1 & $0.05, \mathrm{Ar}$ \\
4 (a) & 0.5 & $0.02, \mathrm{Ar}$ \\
5 (a-e) & 1 & $0.02, \mathrm{Ar}$ \\
6 (a) & 4 & $0.02, \mathrm{Ar}$
\end{tabular}

The experimental series are marked with numbers, and each replication with letters. $\operatorname{Ar}(\mathrm{g})$ or $\mathrm{He}(\mathrm{g})$ were used as inert gases in the chamber.

The brown condensate is found in all the experiments except 1a and 1e, and its weight ranges between 0.10 and $1.65 \mathrm{~g}$ for each repetition. SiC reaction substrates stick strongly together, clogging the system where the condensate appears. SiC particles surrounded by condensate are shown in Figure 3.

As far as microstructure is concerned, EPMA pictures reveal spheres immersed in a matrix with a different molecular weight. Figure 4 shows an elemental mapping of $\mathrm{Si}, \mathrm{O}$, and $\mathrm{C}$ in a selected area of the condensate. The spheres contain more than 90 wt pet silicon, probably close to $100 \mathrm{pct}$. The matrix is made of 40 to $50 \mathrm{wt}$ pet $\mathrm{Si}, 45$ to $55 \mathrm{wt}$ pct $\mathrm{O}$, and up to $5 \mathrm{wt}$ pct $\mathrm{C}$. The sphere diameters range between 0.25 and $2.50 \mu \mathrm{m}$. SE images at higher magnification reveal that the spheres are interconnected by wires (Figures 5 and 6). Both wires and spheres are made of silicon and are immersed in a $\mathrm{SiO}_{2}$ 
matrix. The Si spheres in Figure 6 appear through the $\mathrm{SiO}_{2}$ matrix after tuning topographic and compositional signal at SEM. The nature of the inert gas does not influence the microstructure, nor the composition of the condensates found.

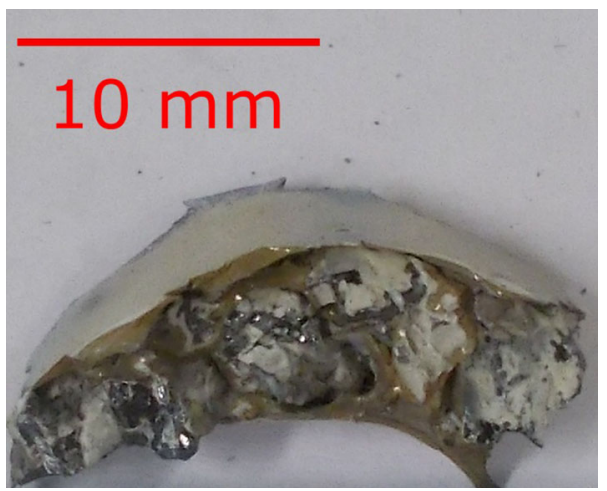

Fig. 3-Brown condensate embedding silicon carbide reaction substrates, sample from experiment $4 \mathrm{a}$.

\section{B. XPS Analysis}

The sample used for XPS is about $5 \mathrm{~mm}$ wide and 1 mm thick (Figure 7). It was collected from experiment 4a. Figure 7 also shows a magnified area, which is a portion of the analyzed XPS sample. The survey spectrum from Figure 8 shows that the amount of carbon is 28.03 at. pct. Minor impurities such as F and $\mathrm{N}$ and $\mathrm{Na}$ count up to $\approx 1$ at. pct. The revealed oxygen and silicon concentrations are 37.2 and 33.81 at. pct. The carbon signal can be analyzed further in the C-1s focused spectrum (Figure 9). The C-C carbon is giving the strongest peak. However, no pure carbon was detected with other techniques. The signal associated to carbides $(282.88 \mathrm{eV})$ is low, but not negligible. Together with EPMA, these results raised some doubts about the presence of carbides in the samples.

As far as $\mathrm{Si}$ is concerned, the $\mathrm{Si}-2 \mathrm{p}$ spectrum is also shown in Figure 9. Peak fitting gave relative molar percentages of $\mathrm{Si}-\mathrm{O}, \mathrm{Si}-\mathrm{C}$, and $\mathrm{Si}-\mathrm{Si}$ of 85, 6, and 9 pct, respectively. $\mathrm{Si}-\mathrm{C}$ and $\mathrm{Si}-\mathrm{Si}$ overlap, as their binding energies are located few tenths of eV from each other. ${ }^{[21]}$ The peak positions for $\mathrm{Si}-\mathrm{Si}, \mathrm{Si}-\mathrm{C}$, and $\mathrm{Si}-\mathrm{O}$ were fitted at $99.4,100.4$, and $103.6 \mathrm{eV}$, respectively.

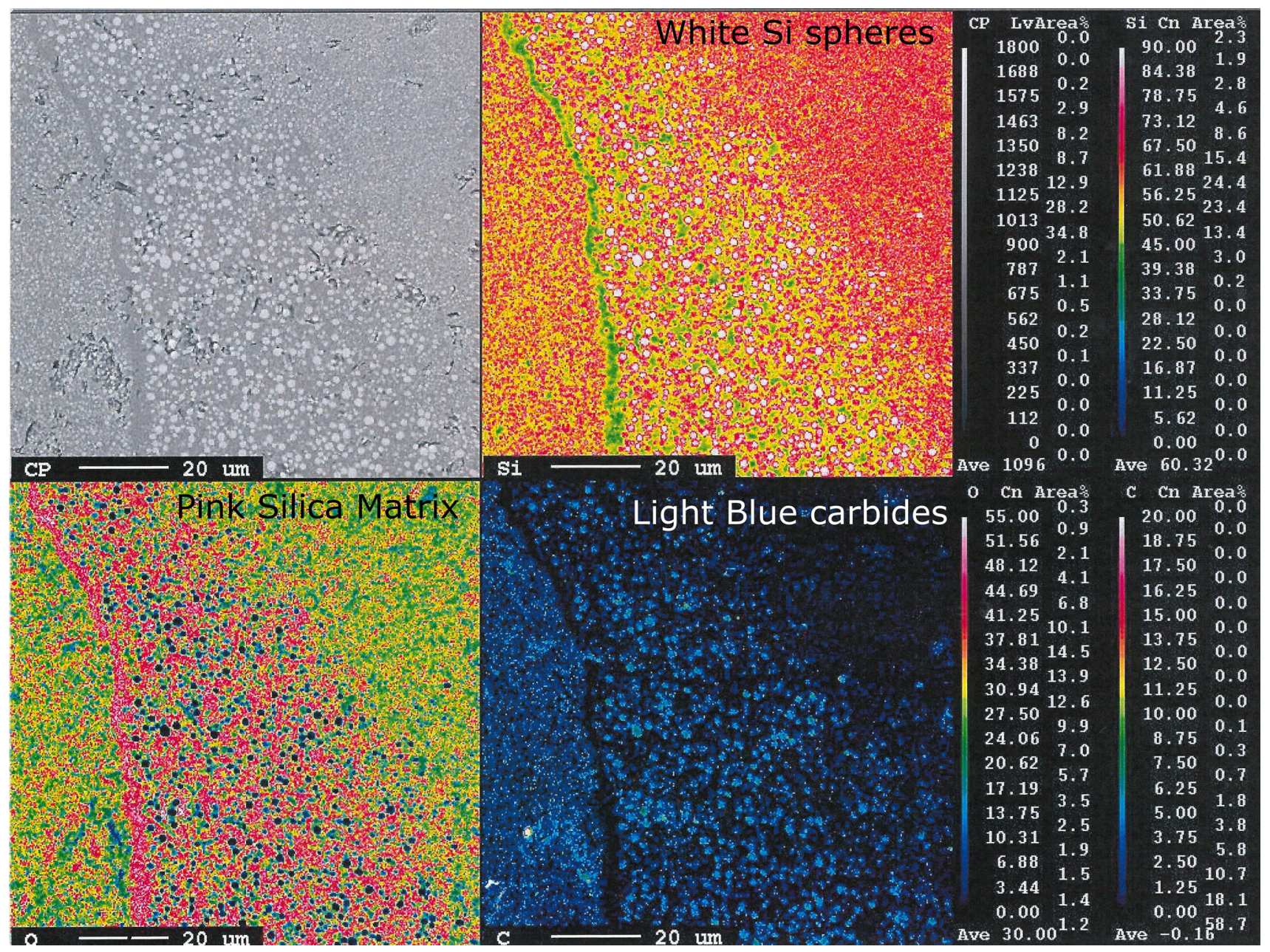

Fig. 4-EPMA mapping of brown condensate, Experiment 4a. The scales report values in wt pct. Revised after, and reprinted with permission of Ref. [18]. 


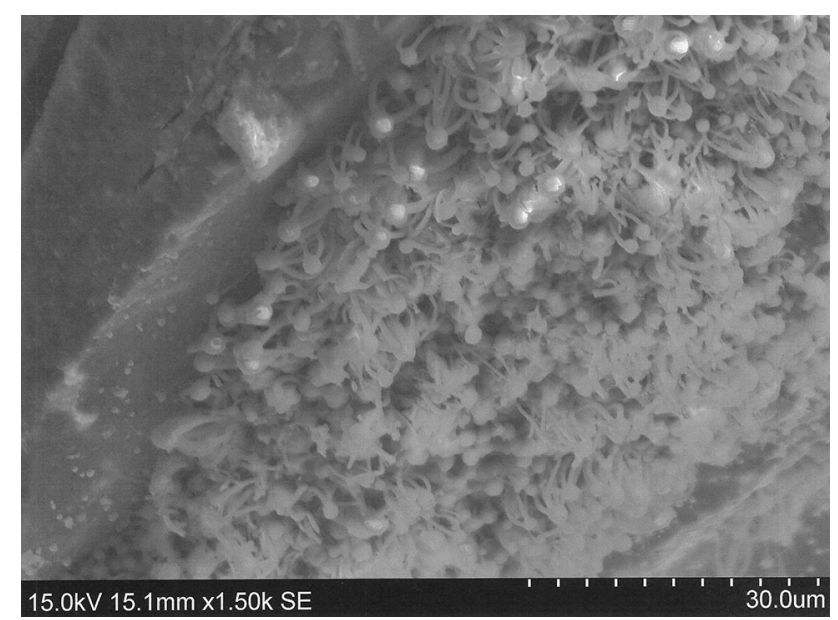

Fig. 5- Si spheres and wires from experiment 1a. Reprinted with permission of Ref. [18]

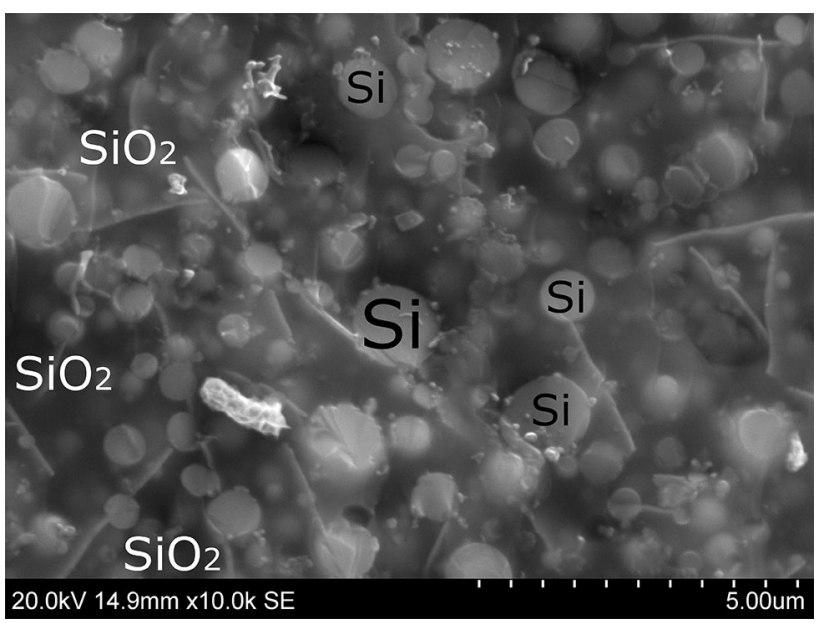

Fig. 6-Top view of brown condensate embedding $\mathrm{Si}$ spheres inside the $\mathrm{SiO}_{2}$ matrix. Sample from experiment $4 \mathrm{a}$.
Possible source of errors in intensity are related to surface contamination of organic impurities. The condensate was accurately separated from the $\mathrm{SiC}$ substrate before XPS analysis; therefore, any carbide signal is merely caused by the condensate itself. Another source of perturbation is that the Si-Si peak overlapping with $\mathrm{Si}-\mathrm{C}$, or its shift by the surface effects of dangling bonds.

\section{FIB Preparation and TEM Analysis}

The brown condensate is a thick and dense material. Through FIB, a thin slab could be extracted and used for TEM analysis. Figure 10 shows how the FIB sample looked like once extracted from the sample surface. The

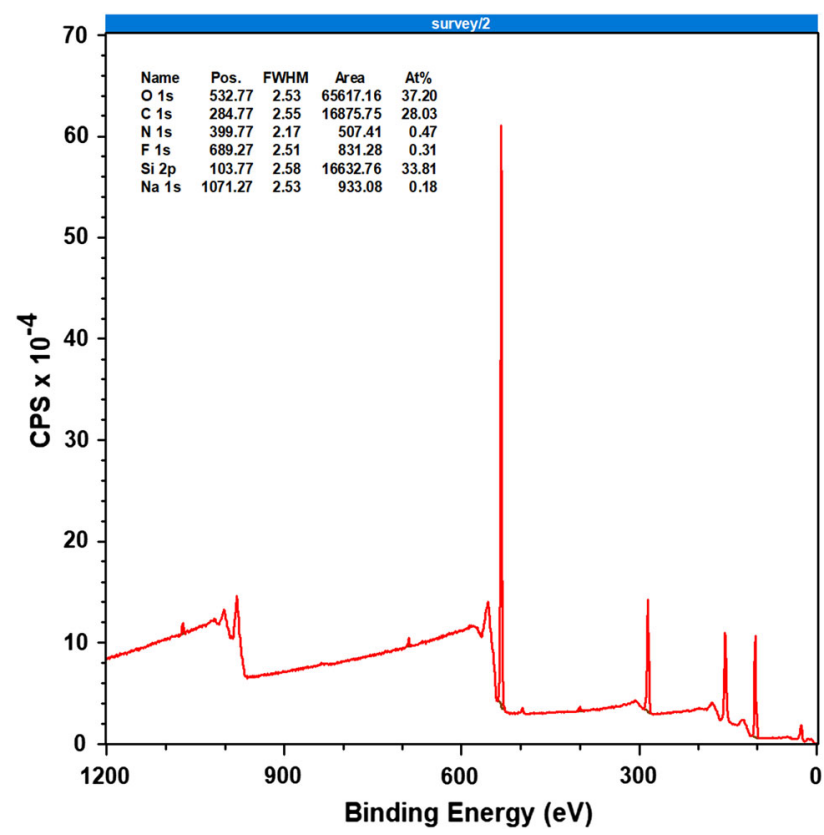

Fig. 8- Survey spectrum of brown condensate from experiment 4a.
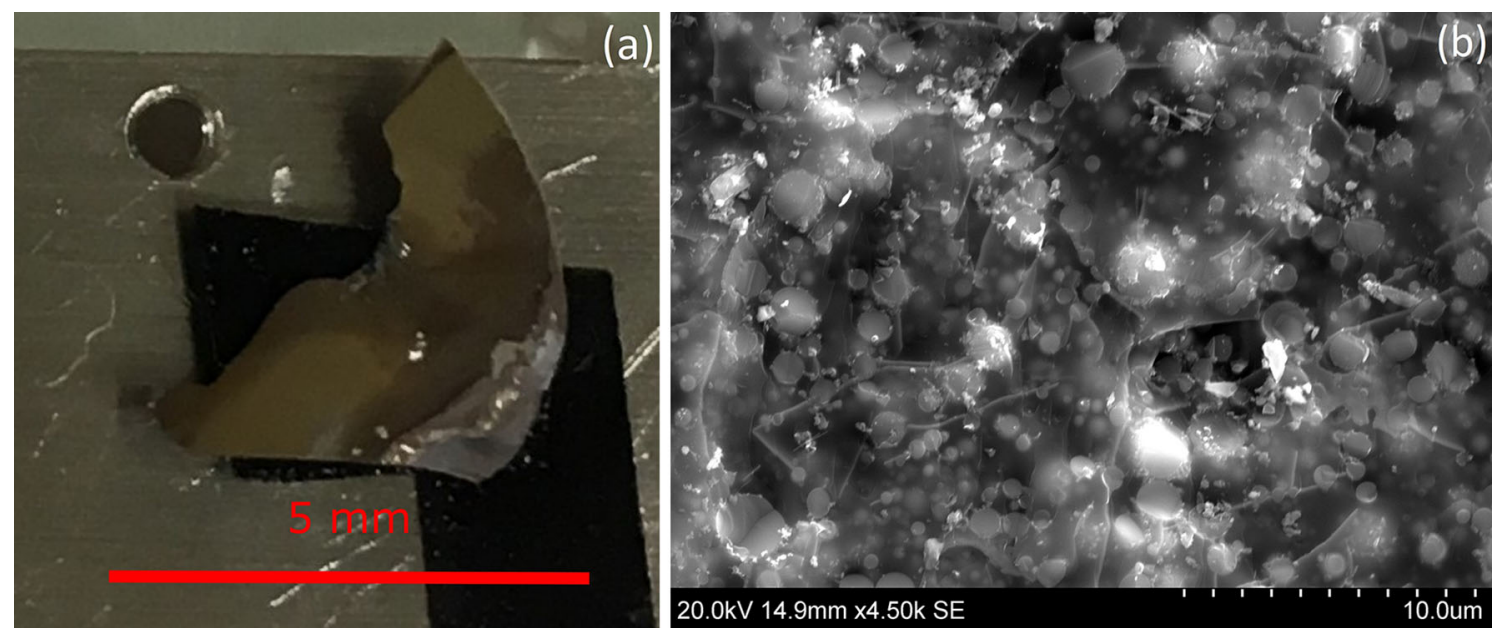

Fig. 7-(a) Brown condensate XPS sample; (b) SE picture from the area chosen for the analysis. 


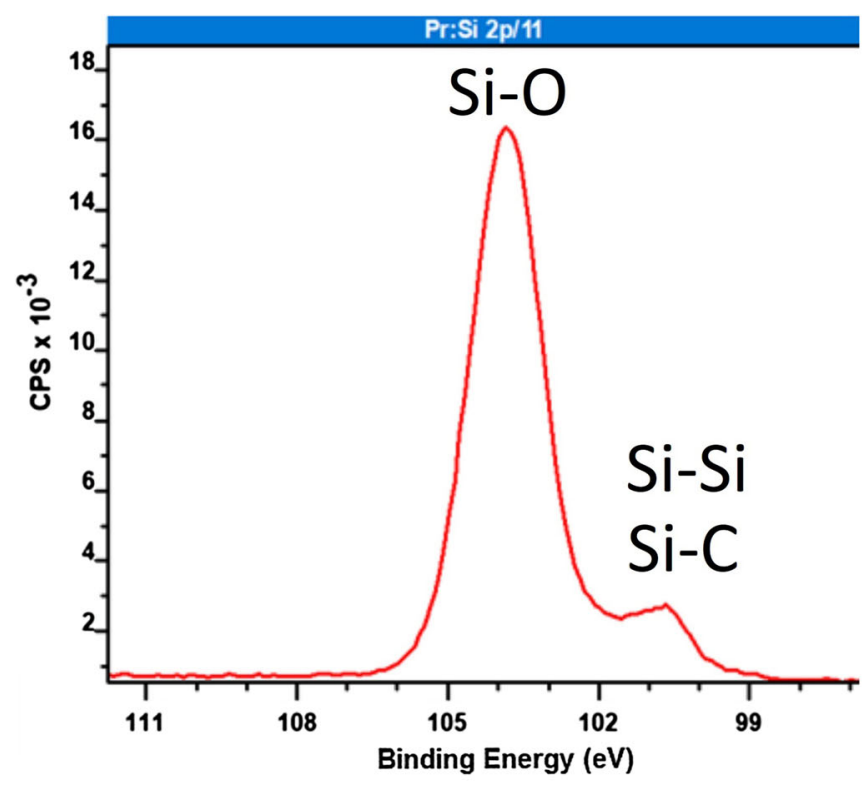

(a)

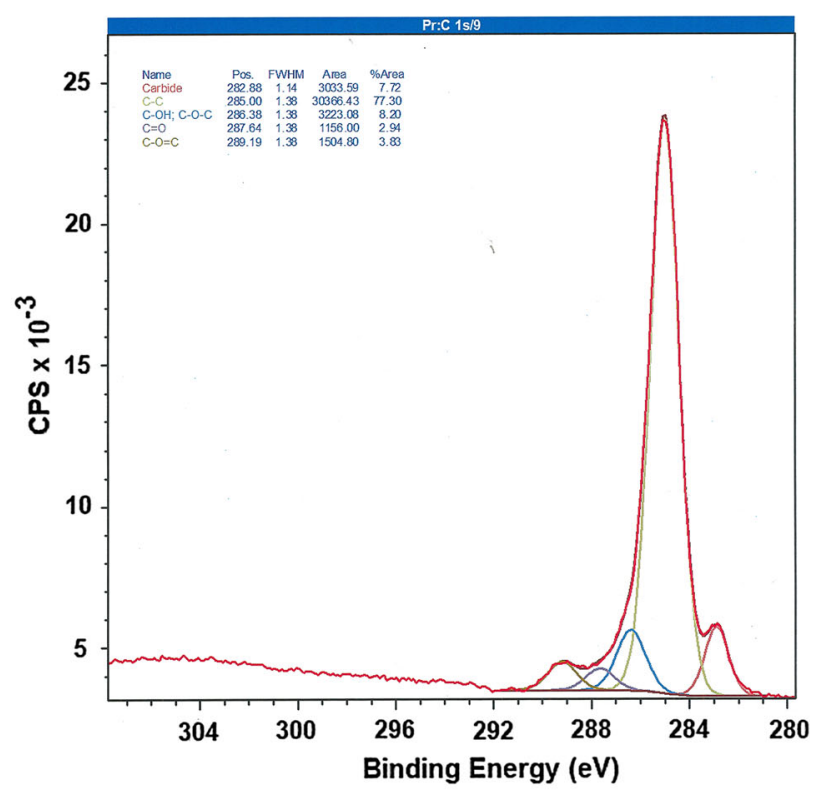

(b)

Fig. 9-XPS spectra for Si-2p (a) and C-1s (b) electrons in brown condensate sample from experiment 4a.
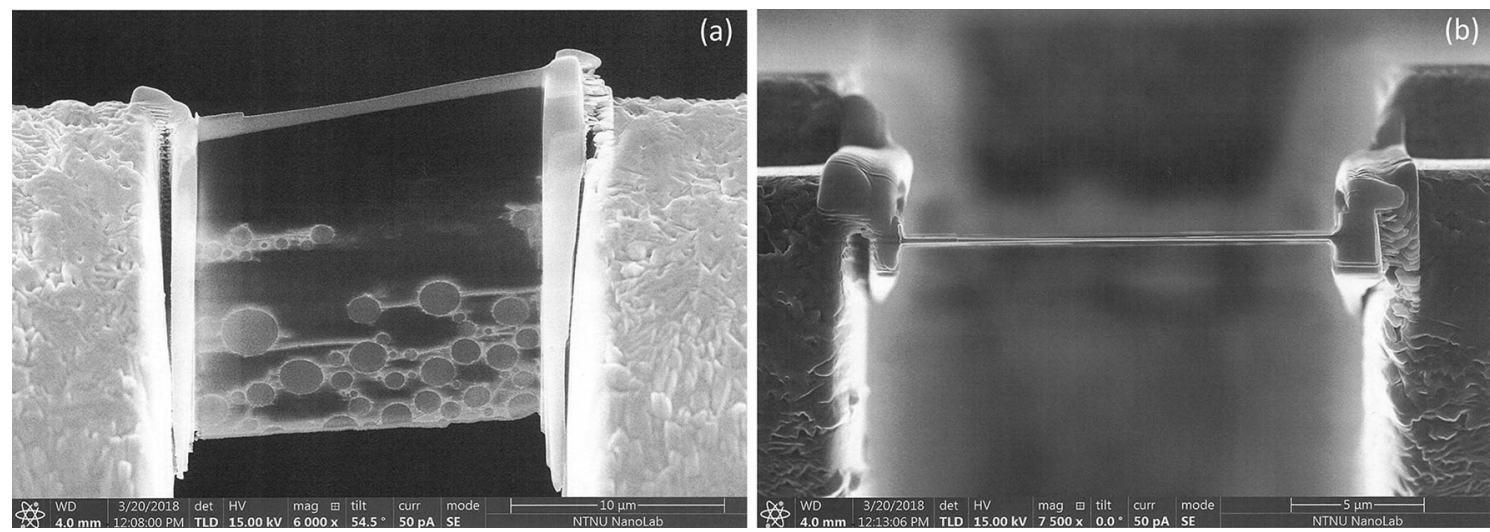

Fig. 10 - Final aspect of the FIB sample of brown condensate, welded on the sides to a TEM sample holder. $(a)$ Frontal view; $(b)$ cross-sectional thickness.

surfaces of the spheres are not perfectly smooth. The wires interconnecting the spheres are easier to notice now (Figure 11), compared to the previous EPMA pictures. The wires width is in the order of magnitude of $10 \mathrm{~nm}$. The light glance at the particle borders is caused by the charging effect of silica.

Energy dispersive X-ray analysis (EDX) on the FIB-sample gave an elemental mapping of a selected area, visualized in Figure 12(a). Si mapping shows three different intensities in signal (Figure 12(b)). A strong signal is present inside the spheres and the wires (yellow). A milder response (orange) comes from the spheres borders, and a weak (green) is detected outside. When it comes to C mapping (Figure 12(c)), the signal is the strongest on those points where the spheres do not show a regular spherical shape. The size of these protuberances ranges between 50 and $150 \mathrm{~nm}$. Only the largest spheres show relevant amounts of carbon on their boundaries. Low amounts of carbon are detected both inside and outside of the spheres. The oxygen mapping (Figure 12(d)) shows the opposite of Figure 12(b). A weak signal (blue) comes from the spheres, a mild one is detected at the interface (green), and a strong response is located in the rest of the system (orange).

\section{D. $C O(g)$ and Temperature Measurements}

Figure 13 shows the temperature measurements when the thermocouple was located at the position where the brown condensate was found. Temperature measurements and estimation of temperature gradients in the chamber found that the brown condensate generates between $1410{ }^{\circ} \mathrm{C}$ and $1500{ }^{\circ} \mathrm{C}(1683 \mathrm{~K}$ and $1773 \mathrm{~K})$ for series 1 , and $1700{ }^{\circ} \mathrm{C}$ and $1780{ }^{\circ} \mathrm{C}(1973 \mathrm{~K}$ and $2053 \mathrm{~K})$ 

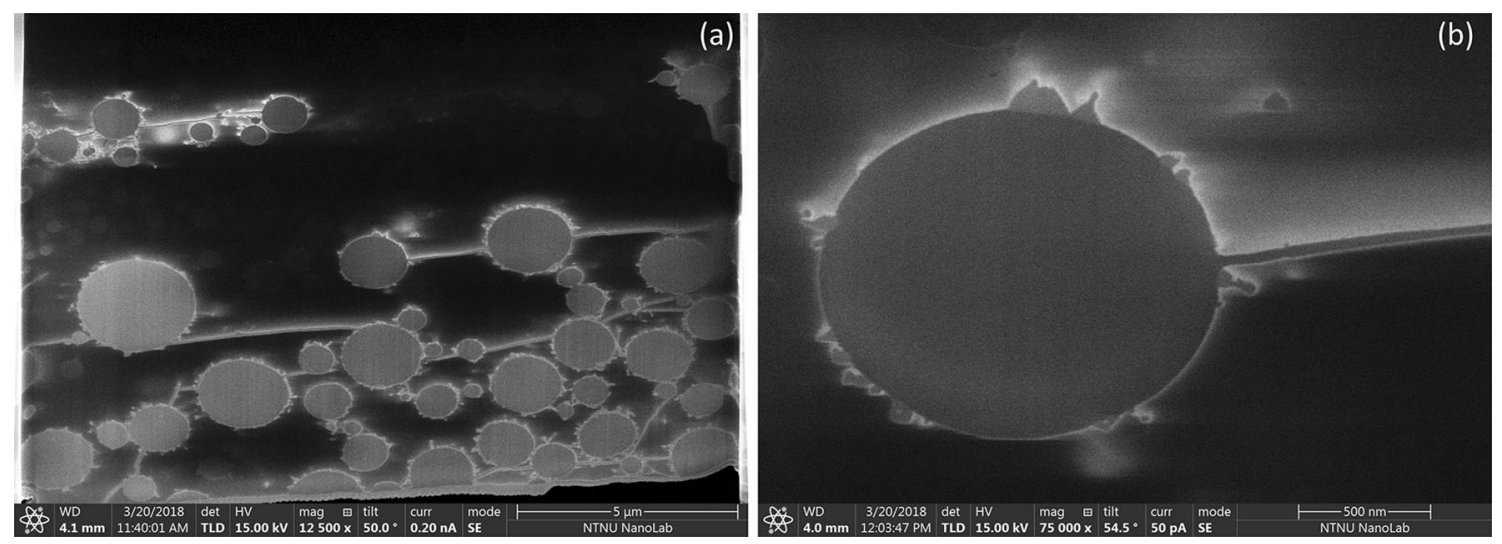

Fig. 11-(a) Si spheres in the FIB-sample; (b) protuberances on the surface of a Si particle.
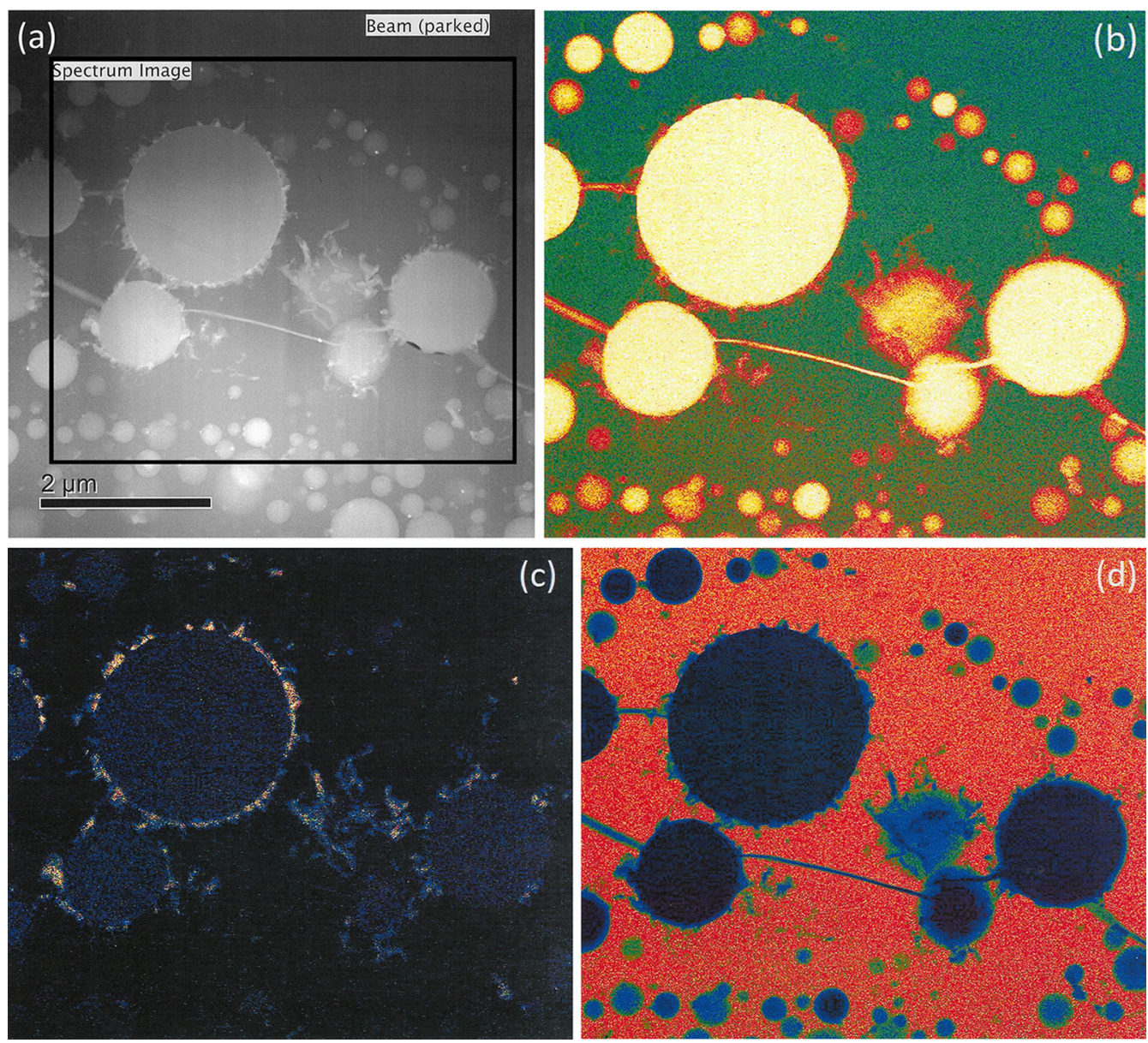

Fig. 12- Original TEM brightfield picture (a). Mapping of Si (b), C (c), and $\mathrm{O}(d)$.

for series 3 to 5 . The temperature at the thermocouple remains constant for at least 45 minutes, once the temperature plateau point is reached.

The gas analyzer measurements can quantitate the reaction time. Gas production would occur between $t \approx 25$ to 30 minutes and $t \approx 55$ to 60 minutes. The interval of time during which the gas is generated is
$\Delta t \approx 30$ minutes, regardless of the applied inert gas flow. According to Reaction [-2], $\mathrm{CO}(\mathrm{g})$ is produced together with $\mathrm{SiO}(\mathrm{g})$ from the $\mathrm{SiO}_{2}-\mathrm{SiC}$ pellets in the gas production chamber. Thus, $\mathrm{SiO}(\mathrm{g})$ is also developed in a time interval of 30 minutes. At $t>60$ minutes, the condensate is held at a constant temperature under flowing $\operatorname{Ar}(\mathrm{g})$ or $\mathrm{He}(\mathrm{g})$. 


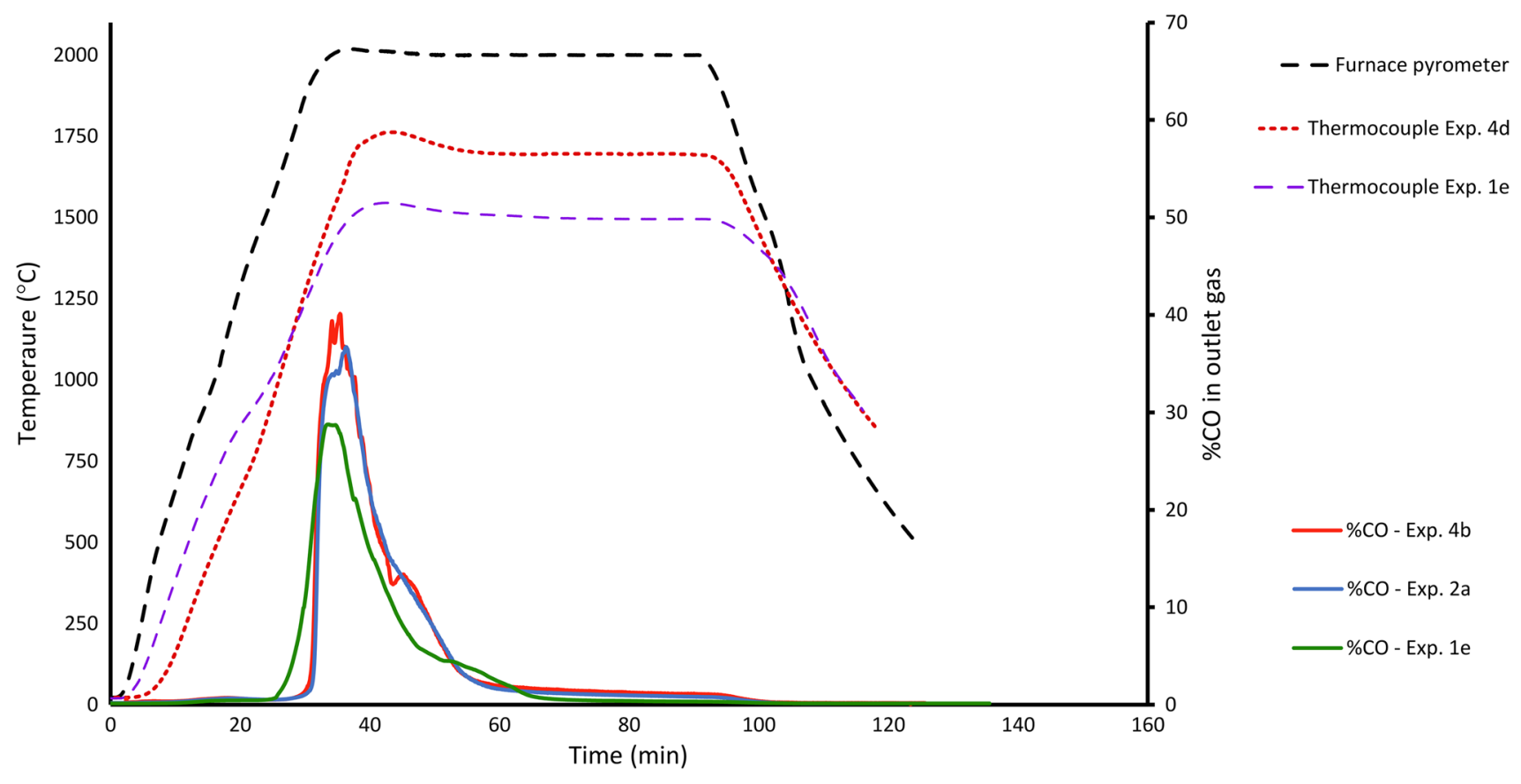

Fig. 13- Gas production and thermal history recorded at position where the brown condensate was found.

\section{DISCUSSION}

\section{A. Formation Mechanism}

The morphology of the condensate matches with previous studies. ${ }^{[2,3,6,10,17-20]}$ The condensate generates at temperatures between $1410{ }^{\circ} \mathrm{C}$ and $1780{ }^{\circ} \mathrm{C}(1683 \mathrm{~K}$ and $2053 \mathrm{~K}$ ), according to the experimental results. The temperature of formation of the condensate is high enough to allow melting of silicon $\left(\mathrm{T}_{\mathrm{m}}=1687 \mathrm{~K}\right)$ and softening (or eventually melting) of amorphous silica $\left(\mathrm{T}_{\mathrm{m}}=1996 \mathrm{~K}\right)$. During cooling, the condensate encounters a temperature interval when silicon is liquid, whereas the matrix is solid. Si assumes a spherical shape and enlarges to reach its lowest internal energy value. Silicon and silica behave like an emulsion. It could be that the largest spheres would grow at the expense of the small ones, through an Ostwald-ripening mechanism. It is important to underline that growth can take place only while both silica and silicon are liquids.

One should wonder about the formation of wires interconnecting the spheres. Diffusion of liquid silicon through solid silica cannot be considered as the cause of the generation of wires. If that was the case, Si would be distributed radially, and its signal would slowly fade inside $\mathrm{SiO}_{2}$. Instead, sharp interfaces are present between the two phases. The wires could be cracks, which were filled with liquid silicon while cooling. Between approximately $1700{ }^{\circ} \mathrm{C}$ and $1400{ }^{\circ} \mathrm{C}(1973 \mathrm{~K}$ to $1673 \mathrm{~K}$ ), the silica matrix would be solid, but silicon would be still liquid. Silicon expands when it solidifies. Cracks in the matrix would develop by mechanical dilation stresses. Liquid silicon could stream through the matrix cracks, then solidify, and give the final microstructure.
Looking closer into the spherical structure, crystallographic defects are widely spread. Figure 14(a) shows a twinning defect, typical of silicon solidification from liquid state. Figures 14(b) and (c) show the differences between the bulk and the twinning pattern. Their signals are collected from the areas marked on Figure 14(a). The bulk diffraction pattern of the sphere coincides with a reference diffraction pattern of pure Si. Silicon is not amorphous in the $\mathrm{Si}-\mathrm{SiO}_{2}$ condensate.

The pattern at the twinning represents a $\sum 3\{111\}$ grain boundary. $\sum 3$ twins are also called coherent twin boundaries, and they are often found in multicrystalline silicon. Such defects can influence the accommodation of iron impurities, according to their orientation and thermal history of cooling, as documented by. ${ }^{[22-24]}$

Temperatures vary in a small space due to local exothermicity of Reactions [1 through 3]. The solubility of Fe in Si might be affected. It is possible that Fe can be trapped in the $\mathrm{Si}_{-} \mathrm{SiO}_{2}$ condensate. This can be a relevant information for ferrosilicon alloys production, where an iron source is added to the charge. However, the presence of Fe was not analyzed in the current study, as the chosen raw materials contained only traces of $\mathrm{Fe}_{2} \mathrm{O}_{3}$.

\section{B. Formation of $\mathrm{SiC}$ in the $\mathrm{Si}-\mathrm{SiO}_{2}$ Compound}

The composition of the brown condensate does not match with the products of Reaction [1] completely, because of the presence of carbon. The material located around the spheres is expected to be $\mathrm{SiC}$ crystals. As seen in the TEM results, both $\mathrm{Si}$ and $\mathrm{C}$ present at the spheres borders. The phase rule will limit the number of phases available. Pure carbon would not be stable in a 

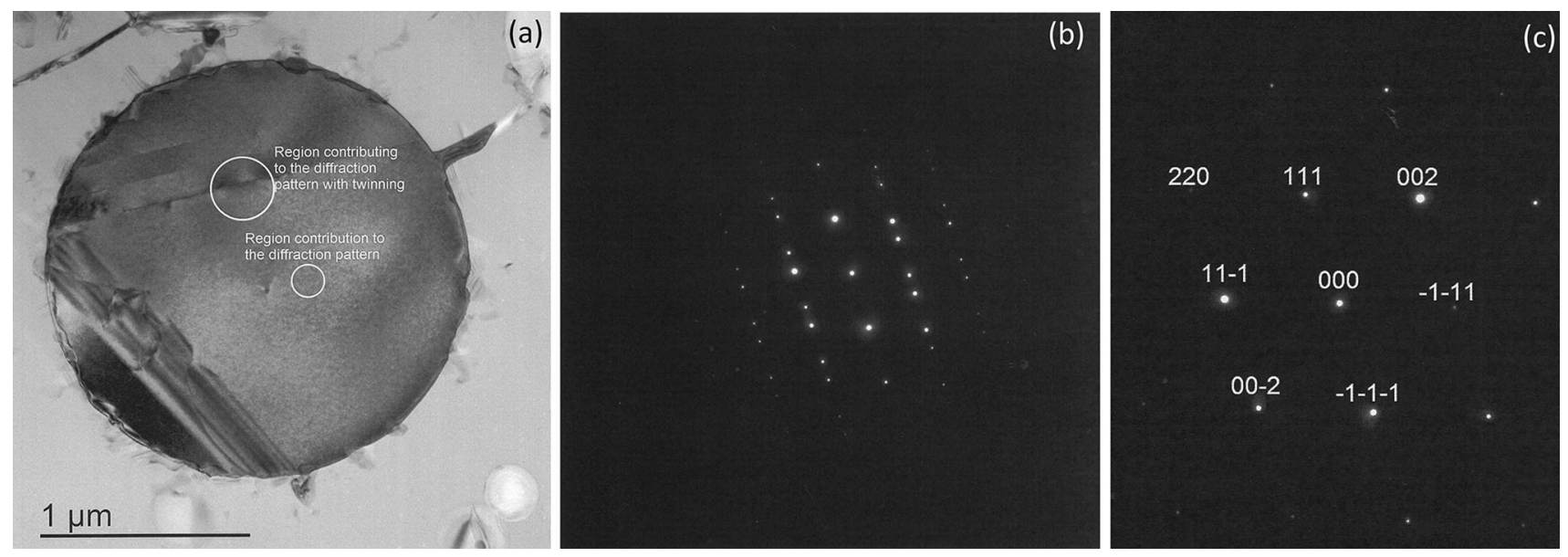

Fig. $14-(a)$ Sphere used for diffraction pattern; $(b, c)$ diffraction pattern with twinning and without twinning, indexed.

system where $\mathrm{Si}, \mathrm{SiO}_{2} \mathrm{SiC}$ and a gas phase are already coexisting, at fixed $\mathrm{T}$ and pressure. A secondary reaction should be proposed together with Reaction [1] for the formation of $\mathrm{Si}_{-} \mathrm{SiO}_{2}$ condensate. Hence two different hypotheses could be considered to explain the presence of $\mathrm{SiC}$ in the system.

\section{Dissolution of carbon in liquid silicon} and precipitation of $\mathrm{SiC}$

The main carbon source in the system will be the $\mathrm{CO}(\mathrm{g})$. EDX mapping of $\mathrm{C}$ in all the spheres shows a negligible signal, which is not quantitatively reliable. The signal could be attributed to the dissolved carbon in silicon, but also to scattering effects of the $\mathrm{SiC}$ crystallites in the surrounding areas. Many of the large spheres show $\mathrm{SiC}$ crystallites, whereas the smallest ones do not. However, the small spheres might not be large enough to dissolve enough carbon. In this case, carbon could not be released as $\mathrm{SiC}$. The literature regarding carbon dissolution in liquid silicon is in heavy contrast. However, it is possible to understand that the order of magnitude of $\mathrm{C}$ dissolution ranges between $10^{-2}$ and $10^{-4}$ at. pct C. ${ }^{[25]} \mathrm{An}$ equation written by Durand and Duby ${ }^{[26]}$ assesses that the molar fraction of carbon in liquid silicon at a fixed temperature between $1687 \mathrm{~K}$ and $3103 \mathrm{~K}$ is

$$
\log \left(X_{\mathrm{C}}^{\mathrm{L}}\right)=2.714-\frac{10623}{T(\mathrm{~K})}
$$

after extrapolation of a collection of works. The law is valid when liquid silicon is in equilibrium with $\mathrm{SiC}$ and dissolved $\mathrm{C}$. This law will be used as reference for the following calculations.

For $T=1973 \mathrm{~K}$, the theoretical amount of $X_{\mathrm{C}}^{\mathrm{L}}$ is 0.002 . This corresponds to a 0.2 at. pet $\mathrm{C}$ dissolved in liquid silicon before segregation.

The volumes of $\mathrm{SiC}$ at the sphere border and a sphere itself can be computed. The moles of each phase can be calculated and related to the equilibrium composition of dissolved C in Si. Figure 15(c) can be taken as reference for the estimation. The ratio between the sum of the $\mathrm{SiC}$ crystallites area in the picture and the area of the sphere without the crystallites is $15 \mathrm{pct}$, according to a graphic estimation by Image $\mathrm{J}($. Assuming the $\mathrm{SiC}$ crystallites to be spherical, the corresponding volume ratio is 6 pct. Starting from a mixture of $6 \mathrm{vol}$ pct $\mathrm{SiC}$ and $94 \mathrm{vol}$ pct $\mathrm{Si}$, about 5 at. pct carbon is found. If this value is compared to Eq. [5], the amount of $\mathrm{SiC}$ generated at the sphere boundary is too large to attribute the formation of $\mathrm{SiC}$ merely to the precipitation of carbon from liquid silicon. Besides, as the sample is a thin slice of condensate, $\mathrm{SiC}$ could be present on other positions of the sphere surface. Additional carbon could accumulate inside the silicon spheres, but quantitative analysis is challenging at such small scale.

As silicon is cooling (or its temperature being constant), the carbon saturation limit is decreasing and $\mathrm{SiC}$ will precipitate. Silicon cannot dissolve more carbon unless the temperature is increased again. Therefore this effect should be relevant only while the gas temperature is increasing, and condensation occurs at the same time. A new mechanism must be proposed to explain a higher amount of $\mathrm{SiC}$ formation in the condensate.

\section{Reaction between Si and flowing $\mathrm{CO}(\mathrm{g})$}

It could be proposed that liquid $\mathrm{Si}$ produced from $\mathrm{SiO}(\mathrm{g})$ disproportionation interacts with $\mathrm{CO}(\mathrm{g})$ through Reaction [5]

$$
3 \mathrm{Si}(1)+2 \mathrm{CO}(\mathrm{g}) \rightarrow 2 \mathrm{SiC}(\mathrm{s})+\mathrm{SiO}_{2}(\mathrm{~g})
$$

The $\mathrm{SiC}$ protuberances could be the starting step of a nanowires growth process, which stopped because of low permeation of the gas through the $\mathrm{SiO}_{2}$ dense liquid matrix. $\mathrm{SiC}$ would be incorporated in the $\mathrm{Si}-\mathrm{SiO}_{2}$ condensate over time, and $\mathrm{SiC}$ growth would stop while cooling. The crystallites found in Figure 15 resemble small clusters, from which nanowires growth could be possible. Grown $\mathrm{SiC}$ nanofibers may be incorporated in the condensate over time.

In Reaction [5] such fibers can be covered in $\mathrm{SiO}_{2}$ oxides or $\mathrm{SiO}_{\mathrm{x}}$ suboxides. If the temperature is low enough, $\mathrm{SiO}_{\mathrm{x}}-\mathrm{SiC}$ nanowires could generate from $\mathrm{Si}(\mathrm{l})$ and $\mathrm{CO}(\mathrm{g}) \cdot \operatorname{Lim}^{[27]}$ and Antipox ${ }^{[28]}$ discovered that reaction between $\mathrm{Si}$ powders and $\mathrm{CO}(\mathrm{g})$ at $1573 \mathrm{~K}$ to 

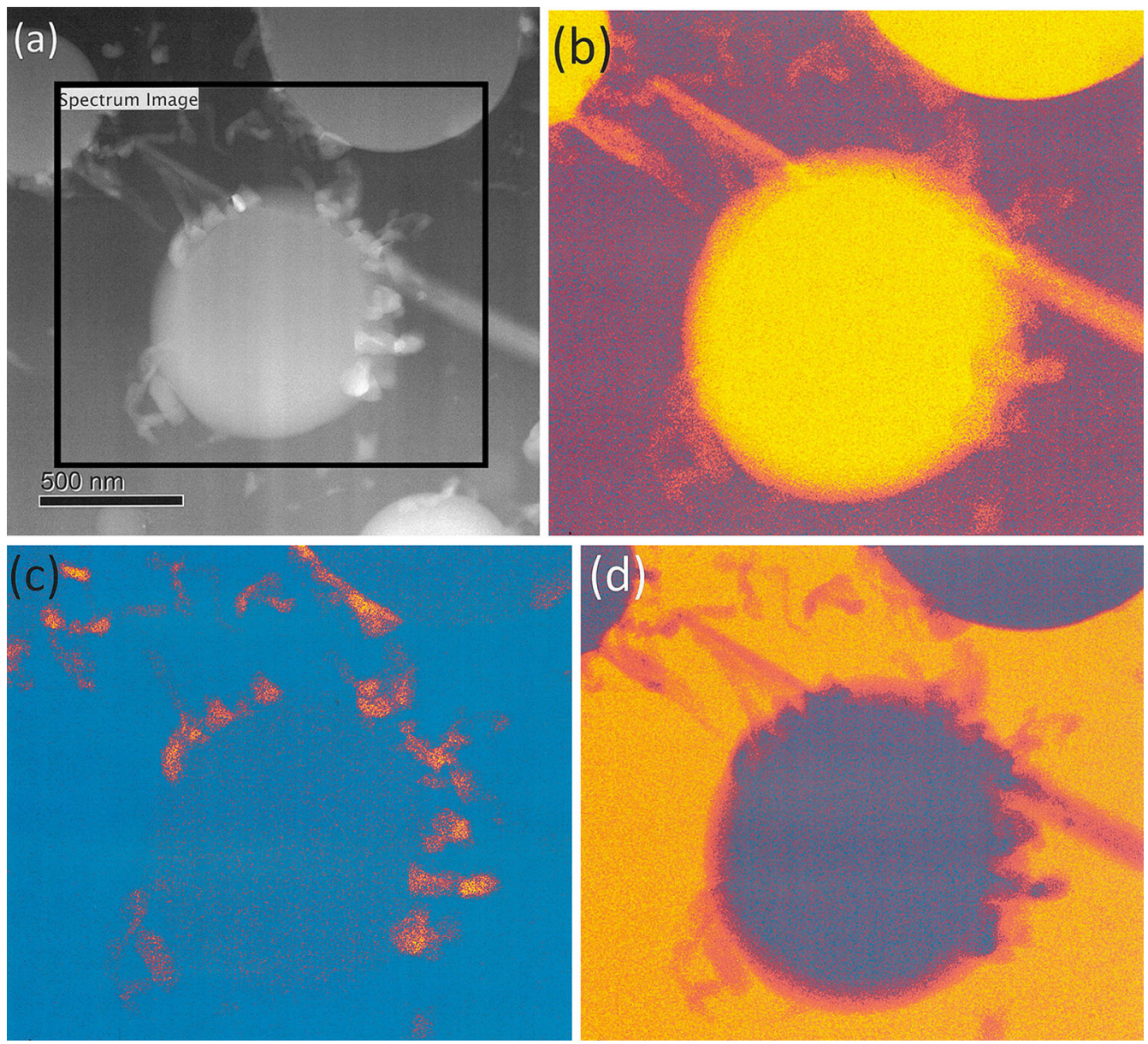

Fig. 15-Elemental EDX mapping of a sphere collected from the FIB-sample: survey area $(a)$. Silicon (b), carbon $(c)$ and oxygen $(d)$ mapping.

$1673 \mathrm{~K}$ can form $\mathrm{SiO}_{2}$-SiC nanowires with diameters ranging between 50 and $100 \mathrm{~nm}$. Being the crystallites diameter in the current study located in the same order of magnitude, the mechanism can be considered as a valid hypothesis. $\mathrm{SiC}$ and $\mathrm{SiO}_{\mathrm{x}}$ clusters are the bases for the growth of $\mathrm{SiO}_{\mathrm{x}}$-coated $\mathrm{SiC}$ nanowires. ${ }^{[29-35]}$

\section{Thermodynamics and Equilibrium Calculations}

\section{Equilibrium calculations on Si-C-O system}

The equilibrium compositions of gaseous phases are compared with the experimental conditions. The curves in Figure 16 visualize temperatures and partial pressures of $\mathrm{SiO}(\mathrm{g})$ at equilibrium conditions, for Reactions [1 through 5]. The curves are marked with the reaction equilibria and the reaction number in parenthesis. If a chosen temperature and partial pressure condition lies at the left of a reaction curve, the reaction equilibrium is shifted to the left-hand term of the equilibrium. To compute these lines, equilibrium constants $K_{\text {eq }}$ were collected from the software HSC Chemistry $9 \AA$. The curves are shifted to higher temperatures with respect to standard condition, since the total pressure is $1.5 \mathrm{~atm}$. One can see the difference by comparing Figure 16 with thermodynamic calculation at $1 \mathrm{~atm} .{ }^{[7]}$
The dashed lines show the temperature and pressure intervals in which condensation occurred by both Reactions [1] and [2]. The edges of these lines have coordinates $\left(\mathrm{T}_{\mathrm{SiO}, \text { in }} ; \mathrm{p}_{\mathrm{SiO}, \text { in }}\right)$ and $\left(\mathrm{T}_{\mathrm{SiO} . \text { out }} ; \mathrm{p}_{\mathrm{SiO}, \text { out }}\right)$. The subscript "in" refers to the gas before it enters the condensation chamber. The subscript "out" refers to the point at which no more condensation is observed.

Temperatures are measured from the thermal gradient computation. Partial pressures are calculated, based on the number of moles of $\mathrm{SiO}(\mathrm{g})$ and $\mathrm{CO}(\mathrm{g})$.

$\mathrm{p}_{\mathrm{SiO} \text {,in }}$ is the molar fraction of $\mathrm{SiO}(\mathrm{g})$ in the gas phase, before condensation starts. The starting moles of $\mathrm{SiO}(\mathrm{g})$ and $\mathrm{CO}(\mathrm{g})$ are fixed for all the experiments. The chosen composition and weight of $\mathrm{SiO}_{2}-\mathrm{SiC}$ pellets produce $0.375 \mathrm{~mol} \mathrm{SiO}(\mathrm{g})$ and $0.125 \mathrm{~mol} \mathrm{CO}(\mathrm{g})$ in every experiment, according to the stoichiometry of Reaction $[-2]$. The inert gas moles will change the partial pressure, as shown in Table IV.

$\mathrm{p}_{\mathrm{SiO} \text {,out }}$ is the molar fraction of $\mathrm{SiO}(\mathrm{g})$ in the gas as condensation stopped. The number of moles of $\mathrm{SiO}(\mathrm{g})$ is the difference between two terms. The first is the starting moles of $\mathrm{SiO}(\mathrm{g})$ and $\mathrm{CO}(\mathrm{g})$, which were already computed for $p_{\mathrm{SiO}, \text { in }}$. The second is the number of moles of $\mathrm{SiO}(\mathrm{g})$ and $\mathrm{CO}(\mathrm{g})$ used for the condensation reactions. This term is computed from the amount of condensate produced, according to Reactions [1] and [2]. 


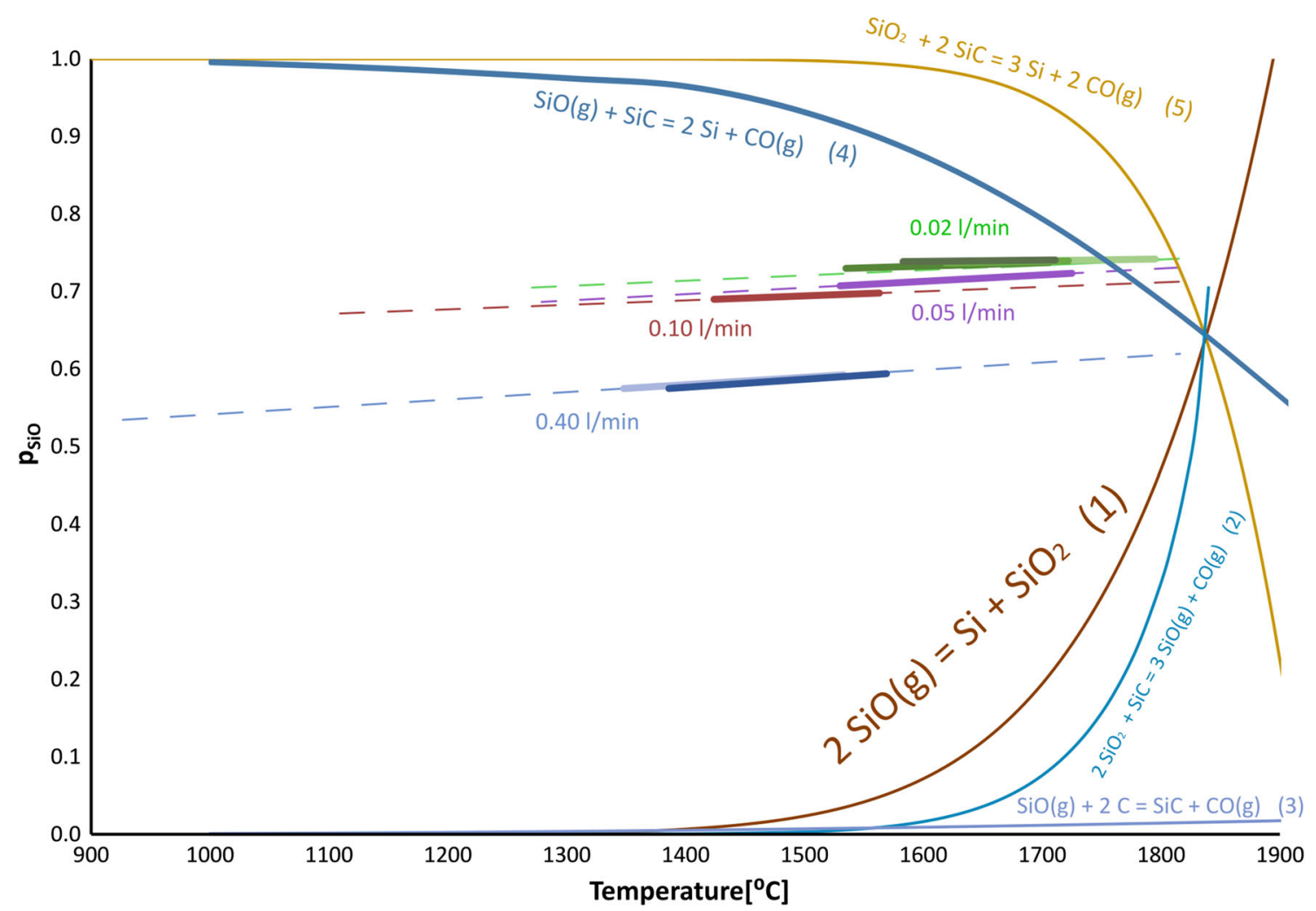

Fig. 16-Equilibrium partial pressure of $\mathrm{SiO}(\mathrm{g})$ Reactions [1 through 5] and comparison with $\mathrm{p}_{\mathrm{SiO}}$ at different inert gas flows.

Table IV. Partial Pressures of $\mathrm{SiO}(\mathrm{g})$, Temperatures, and Condensate's Mass Measured in Each Setup

\begin{tabular}{|c|c|c|c|c|c|c|c|c|c|c|c|}
\hline \multirow{3}{*}{$\begin{array}{l}\text { Gas Flow }(1 / \mathrm{min}) \\
\text { Holding Time } \\
\text { Experiment }\end{array}$} & \multirow{2}{*}{\multicolumn{2}{|c|}{0.4}} & \multirow{3}{*}{$\begin{array}{l}0.1 \\
1 \mathrm{~h} \\
2 \mathrm{a}\end{array}$} & \multirow{3}{*}{$\begin{array}{l}0.05 \\
1 \mathrm{~h} \\
3 \mathrm{a}\end{array}$} & \multicolumn{7}{|c|}{0.02} \\
\hline & & & & & \multirow{2}{*}{$\begin{array}{c}0.5 \mathrm{~h} \\
4 \mathrm{a}\end{array}$} & \multicolumn{5}{|c|}{$1 \mathrm{~h}$} & \multirow{2}{*}{$\begin{array}{c}4 \mathrm{~h} \\
6 \mathrm{a}\end{array}$} \\
\hline & 1a & $1 b$ & & & & $5 \mathrm{a}$ & $5 b$ & $5 \mathrm{c}$ & $5 \mathrm{~d}$ & $5 e$ & \\
\hline $\mathrm{p}_{\mathrm{SiO}, \mathrm{in}}$ & 0.619 & 0.619 & 0.712 & 0.731 & 0.742 & 0.742 & 0.742 & 0.742 & 0.742 & 0.742 & 0.742 \\
\hline $\mathrm{p}_{\mathrm{SiO}, \mathrm{R} 1, \mathrm{start}}$ & 0.594 & 0.592 & 0.698 & 0.723 & 0.738 & 0.741 & 0.742 & 0.738 & 0.737 & 0.739 & 0.741 \\
\hline $\mathrm{p}_{\mathrm{SiO}, \mathrm{R} 1, \mathrm{stop}}$ & 0.575 & 0.575 & 0.690 & 0.707 & 0.737 & 0.732 & 0.739 & 0.734 & 0.730 & 0.736 & 0.738 \\
\hline $\mathrm{p}_{\mathrm{SiO}, \text { out }}$ & 0.537 & 0.534 & 0.671 & 0.686 & 0.731 & 0.705 & 0.732 & 0.723 & 0.715 & 0.731 & 0.731 \\
\hline $\mathrm{T}_{\mathrm{SiO}, \text { in }}\left({ }^{\circ} \mathrm{C}\right)$ & 1815 & 1815 & 1815 & 1815 & 1815 & 1815 & 1815 & 1815 & 1815 & 1815 & 1815 \\
\hline $\mathrm{T}_{\mathrm{SiO}, \mathrm{R} 1, \text { start }}\left({ }^{\circ} \mathrm{C}\right)$ & 1569 & 1533 & 1563 & 1725 & 1666 & 1798 & 1795 & 1706 & 1706 & 1722 & 1711 \\
\hline $\mathrm{T}_{\mathrm{SiO} \mathrm{R} 1, \text { stop }}\left({ }^{\circ} \mathrm{C}\right)$ & 1386 & 1348 & 1424 & 1530 & 1633 & 1666 & 1689 & 1590 & 1535 & 1619 & 1583 \\
\hline $\mathrm{T}_{\text {out }}\left({ }^{\circ} \mathrm{C}\right)$ & 1019 & 924 & 1101 & 1279 & 1377 & 1268 & 1387 & 1268 & 1209 & 1427 & 1134 \\
\hline Mass of $\mathrm{Si}-\mathrm{SiO}_{2}$ Condensate $(\mathrm{g})$ & 0.38 & 0.24 & 0.15 & 1.40 & 0.10 & 1.65 & 0.11 & 0.11 & 0.70 & 0.12 & 0.20 \\
\hline Mass of $\mathrm{SiO}_{2}-\mathrm{SiC}$ Condensate $(\mathrm{g})$ & 1.71 & 2.27 & 2.37 & 2.61 & 0.88 & 3.70 & 0.88 & 1.38 & 1.98 & 1.78 & 1.14 \\
\hline
\end{tabular}

The thicker segments in Figure 15 visualize the temperature and partial pressure ranges where Reaction [1] was noticed, in each experiment. The edges of the segments are named with the subscripts "R1,start" and "R1,stop." Experiments at the same inert gas flow have been collected in groups of lines with similar colors, regardless of the holding time. Table IV collects all the experimental data for temperatures and condensates mass, together with the computed partial pressures.
A higher inert gas flow gives a lower $\mathrm{p}_{\mathrm{SiO}, \text { in }}$ and shifts condensation to temperature intervals located at colder positions.

The amount of $\mathrm{Si}-\mathrm{SiO}_{2}$ condensate tends to be higher when $\mathrm{p}_{\mathrm{SiO} \text {,in }}$ increases, i.e., at lower inert gas flows. The mass of condensate produced should increase with the maximum distance in $\mathrm{p}_{\mathrm{SiO}}$ from the equilibrium curve. However, the mass of $\mathrm{Si}_{-} \mathrm{SiO}_{2}$ condensate changes often between experiments at the same conditions. There should be a correlation between the distance of the 
experimental $\mathrm{p}_{\mathrm{SiO}}$ from its equilibrium value, and the amount of condensate produced. This assertion needs further confirmation.

The mass of the compounds produced is far from the initial $20 \mathrm{~g}$ of pellets. Part of the $\mathrm{SiO}(\mathrm{g})$ was used for Reactions [3] and [4], i.e., the chemical interaction with the graphite crucible.

The experimental conditions lie above the equilibrium curves for Reactions [1 through 3]. A higher flow of inert

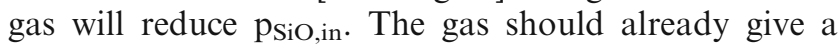
$\mathrm{Si}-\mathrm{SiO}_{2}$ condensate in the gas production chamber. However, only Reaction [3] occurs in the experimental setup, between $1780{ }^{\circ} \mathrm{C}$ and $1810^{\circ} \mathrm{C} .{ }^{[18]}$ Being close to the equilibrium curve, Reaction [2] can shift to $\mathrm{SiO}_{2}$ and $\mathrm{SiC}$ in this temperature range.

The production of Si by Reactions [4] and [5] is not thermodynamically favored. $\mathrm{Si}$ in brown condensate forms only by Reaction [1].

$\mathrm{SiC}$ production is thermodynamically favored by Reaction [5]. The interface between the condensate and the $\mathrm{SiC}$ substrate is sharp. Consequently, one can assume that there is no chemical interaction between the $\mathrm{SiC}$ substrate and the condensate. In other words, the condensate and the substrate do not interact chemically with each other, and all the carbon eventually contained in the condensate is not extracted from the substrate.

The heat of reaction $\Delta H^{\circ}$ of the Reactions [1 through 5] are computed by using HSC Chemistry $9 \AA$. Reactions [1 through 3] and [5] are always exothermic in the temperature ranges typical of industrial furnaces $(1000 \mathrm{~K}$ to $2400 \mathrm{~K})$. The temperature can increase locally in the condensation chamber. $\mathrm{SiO}_{2}$ might have overcome its melting point. Reaction [4] is the only endothermic reaction in the system. Steps in phase transitions occur at the melting point of silicon $(1683 \mathrm{~K})$ and silica (1983 K) (Figure 17).

\section{Assumptions}

This chapter summarizes and discusses the assumptions for the presented calculations.
$\mathrm{T}_{\mathrm{SiO}, \text { in }}$ is assumed to be constant at $1815^{\circ} \mathrm{C}$ for all the experiments. This temperature was measured $20 \mathrm{~mm}$ below the condensation chamber for setup 1a, 2a, and 4e. The assumption is considered valid, although the inert gas enters the gas production chamber at room temperature. The inert gas is assumed to be heated up to $1815^{\circ} \mathrm{C}$ in a considerably short time.

The number of moles of inert gas were found by applying the ideal gas law. The volume of Ar (or He) equals the flow rate times 30 minutes. This is the time in which all the $\mathrm{SiO}_{2}-\mathrm{SiC}$ pellets are consumed, regardless of the holding time of each experiment. Time was estimated from Figure 13, as all the experiments showed a similar trend.

The pellets were completely converted to $\mathrm{SiO}(\mathrm{g})$ and $\mathrm{CO}(\mathrm{g})$ for all the experiments, except Experiment 3a. At this condition, $0.98 \mathrm{~g}$ unreacted pellets were found in the gas production chamber. It was assumed that the leftovers were also a $\mathrm{SiO}_{2}-\mathrm{SiC}$ in a molar ratio 2:1. The moles in the leftovers decrease the partial pressure of $\mathrm{SiO}(\mathrm{g})$ by $5 \times 10^{-4}$.

The gas phase consists mainly of $\mathrm{SiO}(\mathrm{g})$ and $\mathrm{CO}(\mathrm{g})$ only. The partial pressure of $\mathrm{O}_{2}(\mathrm{~g})$ is negligible after inert gas purging and vacuuming procedure.

The moles of $\mathrm{SiO}(\mathrm{g})$ consumed by Reaction [3] were not considered in the calculation of $\mathrm{p}_{\mathrm{SiO} \text {,in. }}$ Part of the $\mathrm{SiO}(\mathrm{g})$ interacts with the graphite cylinder, generating $\mathrm{SiC}$ by Reaction [3]. Si occasionally generated in the gas production chamber, through Reaction [4]. The thickness of the $\mathrm{SiC}$ layer does not exceed $400 \mu \mathrm{m}$ on the walls of the graphite cylinder.

The pressure is varying while the experiment goes on. The furnace is not equipped with a system recording the pressure continuously. The pressure of the outgoing gas is measured at three different instants. For all the experiments, the pressure before the $\mathrm{SiO}(\mathrm{g})$ production reaction was $1.4 \mathrm{~atm}$. Then the pressure increases up to $1.6 \mathrm{~atm}$ when the gas production reaches its maximum extent. Finally, the pressure stabilizes at around $1.5 \mathrm{~atm}$ few minutes after the $\mathrm{CO}(\mathrm{g})$ peak was reached. For

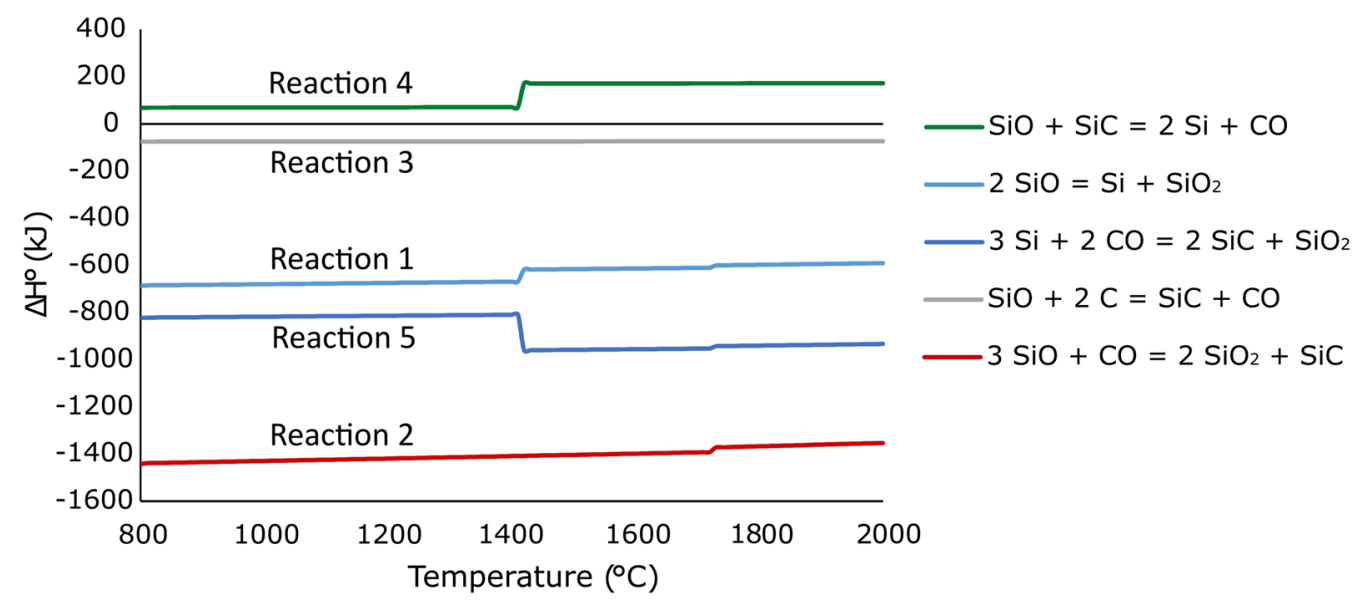

Fig. 17-Temperature dependence of reaction enthalpies for Reactions [1 through 5]. 
simplicity, it will be assumed that the pressure of the system is constant at 1.5 atm through the whole condensation process.

All the solid and liquid phases were assumed pure, with activities equal to one. The gas phase follows the ideal gas law.

The lines plotted in Figure 14 are giving an indicative linear trend. It could be that $\mathrm{p}_{\mathrm{SiO}}$ decreases faster at high temperatures. Most of the condensation products is found between $1300{ }^{\circ} \mathrm{C}$ and $1800{ }^{\circ} \mathrm{C}$. This could affect the slope of the curve.

The $\mathrm{Si}-\mathrm{SiO}_{2}$ mixture was not produced in Experiments 1a and 1d. The condensates were not weighted for experiment 1e. The condensates got strongly stuck on the SiC substrates. Separation and weight would be affected by severe contamination.

The $\mathrm{Si}-\mathrm{SiO}_{2}$ condensate is separated manually from the $\mathrm{SiC}$ substrate. The $\mathrm{SiC}$ particles are weighted both before and after every experiment. The weight of the $\mathrm{SiO}_{2}-\mathrm{SiC}$ condensate is calculated. The weight of the $\mathrm{Si}-\mathrm{SiO}_{2}$ mixture is subtracted from the global increase in weight of the $\mathrm{SiC}$ particle after the experiment. Increase in weight of $\mathrm{SiC}$ substrates is caused by deposition of condensates only.

The position measurements in the crucible might suffer uncertainties, which could lead to errors up to $50{ }^{\circ} \mathrm{C}$. While computing the position's dependence on temperature in the condensation chamber, it was noticed that the temperature varies up to $10^{\circ} \mathrm{C} / \mathrm{mm}$. The maximum size of a $\mathrm{SiC}$ particle is $5 \mathrm{~mm}$. $\mathrm{T}_{\mathrm{SiO}, \mathrm{R} 1 \text {,start }}$,

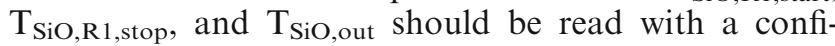
dence interval of $\pm 50^{\circ} \mathrm{C}$.

\section{CONCLUSION}

A mixture of $\mathrm{SiO}_{2}$ and $\mathrm{SiC}$ powders was used to produce $\mathrm{SiO}(\mathrm{g})$ and $\mathrm{CO}(\mathrm{g})$, according to the reaction $2 \mathrm{SiO}_{2}(\mathrm{~s})+\mathrm{SiC}(\mathrm{s}) \rightarrow 3 \mathrm{SiO}(\mathrm{g})+\mathrm{CO}(\mathrm{g})$. One of the condensed products consists of $\mathrm{Si}$ and $\mathrm{SiO}_{2}$. The microstructure consists of silicon spheres, interconnected by silicon wires and embedded in a silica matrix. The two phases are immiscible. The spherical shape of Si in the compound is the result of the reduction of the surface energy. Once cooling starts, liquid silicon would dilate and cause nanometric-sized cracks in solid silica.

XPS, EPMA, and FIB showed a localized presence of carbon, corresponding to $\mathrm{SiC}$ crystals. Such nanoclusters generated at the $\mathrm{Si}-\mathrm{SiO}_{2}$ interface could have grown from continuous dissolution and precipitation of carbon from liquid silicon. This mechanism is thought to have a minor importance, since the temperature is kept constant for the majority of the experiment. Another proposed mechanism is the nanocluster growth of carbides from silicon. $\mathrm{SiC}$ and $\mathrm{SiO}_{2}$ might generate at the Si surface, whether Si was liquid or solid. Growth could be limited by the weak $\mathrm{SiO}(\mathrm{g})$ and $\mathrm{CO}(\mathrm{g})$ flows through viscous silica.

Equilibrium calculations and temperature measurements show that the $\mathrm{Si}_{-} \mathrm{SiO}_{2}$ condensate develops between $1400{ }^{\circ} \mathrm{C}$ and $1780{ }^{\circ} \mathrm{C}(1673 \mathrm{~K}$ and $2053 \mathrm{~K})$, and $\mathrm{p}_{\mathrm{SiO}}=0.534$ to 0.742 . There are hints of a correlation between the amount of condensate produced and the experimental partial pressure, or its distance from the equilibrium. However, it could be that either the experiments are hard to reproduce, or contamination affected the weighted condensate amount.

\section{ACKNOWLEDGMENTS}

The authors would like to thank Morten Peder Raanes for the EPMA and Ingeborg-Helen Svenum (SINTEF) for the XPS analysis. The TEM work was carried out using NORTEM infrastructure, Grant 197405, TEM Gemini Centre, Norwegian University of Science and Technology (NTNU), Norway. The FIB preparation and the TEM analysis were carried out in collaboration with Per Erik Vullum (SINTEF) and Ragnhild Sæterli (NTNU). Particle size distributions were carried out by Irene Bragstad (SINTEF). The current study was supported by Elkem ASA and the EnergiX program of the Research Council of Norway through project 269431 - SiNoCO2.

\section{OPEN ACCESS}

This article is distributed under the terms of the Creative Commons Attribution 4.0 International License (http://creativecommons.org/licenses/by/4.0/), which permits unrestricted use, distribution, and reproduction in any medium, provided you give appropriate credit to the original author(s) and the source, provide a link to the Creative Commons license, and indicate if changes were made.

\section{REFERENCES}

1. L. Fei: SiC Production Using $\mathrm{SiO}_{2}$ and $\mathrm{C}$ Agglomerates, Doctoral thesis, NTNU, Department of Materials Science and Engineering, 2017

2. J. Vangskåsen: Metal-Producing Reactions in the Carbothermic Silicon Process, 2012, Master thesis, NTNU, Department of Materials Science and Engineering, pp. 3-6.

3. M. Ksiazek, I. Kero: in Takano Int. Symp. Met. All., 2015, pp. 157-66.

4. E. Ringdalen: in Silicon Chem. Sol. Ind. XIII, Kristiansand, Norway, 2016, pp. 269-78.

5. M. Tangstad: Metal Production in Norway, 1st ed., 2013.

6. M. Tangstad, M. Ksiazek, J.E. Andersen: in Silicon Chem. Sol. Ind. XII, Trondheim, Norway, 2014, pp. 19-28.

7. A. Schei, J. Tuset, and H. Tveit: Production of High Silicon Alloys, 1st ed., Tapir, Trondheim, 1998.

8. G. Tranell: in Sustain. Future, Helsinki, Finland, 2010, pp. 709-716.

9. E. Myrhaug: Non Fossil Reduction Materials in the Silicon Process-Properties and Behaviour, Doctoral thesis, NTNU, Department of Materials Science and Engineering, 2003.

10. M. Ksiazek, E. Ringdalen: in Silicon Chem. Sol. Ind. XIII, Kristiansand, Norway, 2016, pp. 33-42.

11. Y. Otani, M. Saito, K. Usui, N. Chino: in 6th Int. Congr. Electroheat, Brighton, 1968, pp. 1-7.

12. A. Schei and O. Sandberg: Selected Topics in High Temperature Chemistry, 1st ed., Elsevier, York, 1966.

13. A. Schei: in H. Rong, H.A. Øye (Eds.), Silicon Chem. Ind., 1992, pp. 11-23.

14. A. Schei: Tidsskr Kjemi Bergves. Met., 1967, vol. 27, pp. 252-58 
15. W. Poch and A. Dietzel: Trans. Nat. Res. Inst. Met., 1962, vol. 14, pp. $22-51$.

16. T. Kurosawa, T. Yagihashi, S. Ochiai, and T. Naramura: Trans. Nat. Res. Inst. Met., 1972, vol. 14, pp. 22-51.

17. M. Tangstad, M. Ksiazek: Investigation of White and Brown Condensate, SINTEF internal report, 2010.

18. A. Broggi, M. Tangstad, E. Ringdalen: in Silicon Chem. Sol. Ind. XIV, Svolvar, Norway, 2018, pp. 139-152.

19. M. Tangstad, M. Ksiazek: in V. Andersen, E. Ringdalen (Eds) Sustain. Future, Helsinki, Finland, 2010, pp. 661-670.

20. L. Brewer and E. Russell: J. Phys. Chem., 1954, vol. 58, pp. 351-58.

21. E.A. Dalchiele, A. Aurora, G. Bernardini, F. Cattaruzza, A. Flamini, P. Pallavicini, R. Zanoni, and F. Decker: J. Electroanal. Chem., 2005, vol. 579, pp. 133-42.

22. J. Chen, D. Yang, T. Sekiguchi, F. Yin, K. Kido, and S. Tsurekawa: J. Appl. Phys., 2004, vol. 96, pp. 5490-95.

23. C. Jun, Y. Deren, and X. Zhenqiang: J. Appl. Phys., 2004, vol. 97, pp. 5490-95.

24. C. Bin, C. Jun, S. Takashi, M. Saito, and K. Koji: J. Appl. Phys., 2009, vol. 105, pp. $1-5$.

25. R.W. Olesinski and G.J. Abbaschian: Bull. Alloy Phase Diagr., 1984, vol. 5, pp. 486-89.

26. F. Durand and J.C. Duby: J. Phase Equilibria, 1999, vol. 20, pp. 61-63.
27. K. Lim: Recovery and Utilisation of Kerf Waste from Silicon Wafering Process, Master thesis, NTNU, Department of Materials Science and Engineering, 2018.

28. A.V. Antipov, R.G. Pavelko, V.G. Sevasty'anov, and N.T. Kuznetsov: Russ. J. Inorg. Chem., 2011, vol. 56, pp. 1517-24.

29. X.J. Wang, J.F. Tian, L.H. Bao, C. Hui, T.Z. Yang, C.M. Shen, H.-J. Gao, F. Liu, and N.S. Xu: J. Appl. Phys., 2007, vol. 102, pp. $1-6$.

30. R. Wu, B. Zha, L. Wang, K. Zhou, and Y. Pan: Phys. Status Solidi A, 2012, vol. 209, pp. 553-58.

31. S.N. Mohammad: J. Vac. Sci. Technol. B, 2008, vol. 26, pp. 19932007.

32. R.-Q. Zhang, Y. Lifshitz, and S.-T. Lee: Adv. Mater., 2003, vol. 15 , pp. $635-40$.

33. P. Hu, S. Dong, K. Gui, X. Deng, and X. Zhang: R. Soc. Chem., 2015, vol. 5, pp. 66403-408.

34. P. Hu, R.-Q. Pan, S. Dong, K. Jin, and X. Zhang: Ceram. Int., 2016, vol. 42, pp. 3625-30.

35. H. Liu, Z. Huang, J. Huang, M. Fang, Y.-G. Liu, and X. Wu: J. Mater. Chem. C, 2014, vol. 2, pp. 7761-67.

Publisher's Note Springer Nature remains neutral with regard to jurisdictional claims in published maps and institutional affiliations. 